\title{
Pioneering a Design-led Approach to Transform Higher Education Services
}

\author{
Heather Madden \\ Cork Institute of Technology \\ Ireland
}

\begin{abstract}
In third level institutions, there are many disparate actors, systems and processes involved in service delivery and too often staff work in silos with little or no understanding of the personal impact of the student journey. The higher education sector endeavors to make all the services we deliver more useful, usable, efficient and student-centred but sometimes there is insufficient consideration of an overall approach to the actual student lifecycle and the supporting of same. The current complexity of the processes can cause frustration for those involved, in particular, front-line staff and students, particularly where there is a lack of cross-functional communication. There is a need to understand the service before introducing products into the service. An effort is now under way in one institute, to consider how Design Thinking could be applied to higher education services, as a series of iterative change projects, with the ambition of long-lasting sustainable change. This paper seeks to review existing literature in order to assess how one can build on previous experience, and make a contribution to the body of knowledge, based on the current dearth of research in the area of Design Thinking in higher education.
\end{abstract}

\section{Introduction}

Cork Institute of Technology (CIT) is a publicly funded higher education provider. It is the largest of Ireland's network of thirteen Institutes of Technology and currently has in the region of 15,000 registered students with approximately 2,000 new entries year on year. Its education, research and training provision spans a wide variety of disciplines, from business and humanities through engineering and science to music, drama, art and design.

In 2011, Senior Management requested a review of current IT systems and a proposal for integration of the same. The problems that existed included issues with data quality and timely availability, lack of online student self-service, isolated enterprise applications and a disconnect between academic business process and the IT solutions needed to support them.
CIT is currently investigating if Design Thinking can be embedded within an existing culture, not just as a once-off project, but as a way of improving and aligning all the processes that make up the entire service. As part of a plan to transform and streamline services to students, a Service Design methodology was recently piloted, which effectively re-designed, aligned and automated some of the key business processes within the student lifecycle.

The next steps are to see if this approach can be used to transform services over the coming years. This paper is one step on a practice-based research journey to ascertain if higher education can use Design Thinking to:

- Improve existing processes,

- Enhance the staff and student experience and

- Ensure the right tools are in place to support staff and students in a third level institute.

Existing literature will be explored under a number of headings in order to gather insights and knowledge on the use of Design Thinking as a change enabler in public sector organisations.

\section{Innovation}

Innovation happens every day and is all around us and it can be anything from breakthrough research that cures a disease or small ideas that help to solve a particular problem in a particular situation. This paper is looking to assess whether design can be a driver for innovation in the higher education sector. There is no one simple definition of what innovation is but it can be considered as a new idea, product or process that leads not only to improvement but 'doing something different rather than doing the same thing better'.

However change cannot always be regarded as innovation since it does not always involve new ideas or does not always lead to improvement in an organisation. Innovation can be defined as the implementation of a new and possibly problem solving idea, practice or material artefact which is regarded as new by the relevant unit of adoption and through which change is brought about [14].

There is a different process of innovation suitable for both public and private sectors and the diverse range of organisations in both. Innovation is not seen 
as a core activity in many public sector organisations, in particular higher education. The inflexible character of these organisations is often the main cause of the scarcity of innovation.

Von Stamm [20] observes that creativity is associated with our thinking, and innovation associated with our behaviour. In order to allow people to think and behave differently in any organisation, the barriers to the collective creativity of that organisation need to be removed, or at least reduced. Many initial innovations will be small quick-wins that are focused on incremental change, and this is a good place to start. Rather than just encouraging people to think of new ideas, transferring those ideas into practice is what fosters real change.

Many people have ideas and a voice but do not get an opportunity to act on their creativity as a result of day-to-day obstacles. In order for creativity to flourish, the right leadership must be in place, which can foster an environment that allows people to ideate, experiment, take risks and explore their hidden talents. Gouillart [9] believes that any organisation that can create a link between business processes, and a team of 'integrative thinkers' [5] will enable boundless opportunities for the future. A model for innovation for the higher education sector is necessary, which can be used to gradually change the reputation of public sector organisations as static, complex and risk averse.

\subsection{Innovation in Higher Education}

In higher education, an environment needs to be cultivated where employees can unleash their capacity for innovation and have both the physical and psychological environment to do so. In order for creativity to become acceptable in the higher education sector, steps need to be taken towards alleviating, and in the long term, removing the barriers to change, and subsequently allowing space for innovation to happen. This innovation must be borne out of co-creation activities encompassing both the employees and customers of the organisation.

Innovation in the public sector can lead to more efficient organisations and better services for the public. In order for innovation to prosper in any organisation, it is necessary to strengthen the incentives for innovation by providing opportunities and skills to employees and management to explore new ways of doing their jobs. This means having the right leadership in place to foster creativity and aligning the culture with new methods over time.

\section{Service Design}

The emergence of Service Design in 1984 as a tool to be used by organisations was a significant step in realising that services should be subject to the same precise analysis as other business operations. Indeed Gloppen [8] acknowledges that there is little research on Service Design as a strategic resource for service organisations. The lack of acceptance by business leaders that Design Thinking can both help them as leaders with their organisation vision and help their employees to problem solve and innovate could be detrimental.

Service Design looks at the design of a service from the user perspective and can be used to create new or improve existing services. User experience and the involvement of users in the co-design process is paramount to what Service Design stands for [17]. Service Design is a holistic integrative approach that uses a wide range of tools and methods to deliver more value primarily to the end user but also creating a more efficient and effective organisation in the process. The service interface in Fig. 1 is made up of a number of touchpoints that the user of the service has with an organisation. A touchpoint is an interaction point with one of the elements of the service offering.

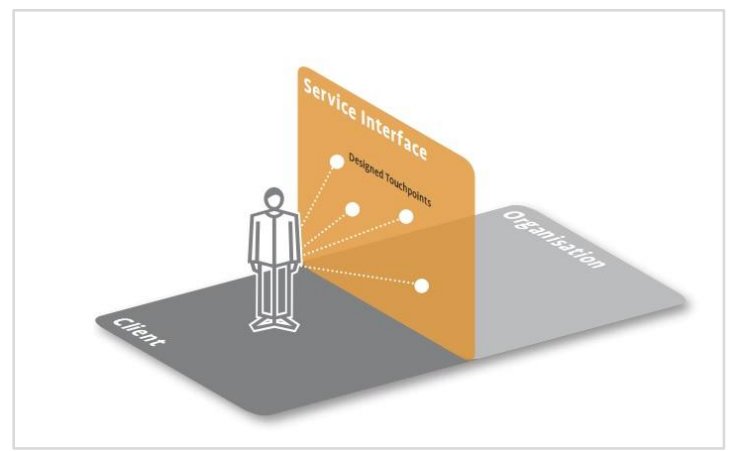

Figure 1. Service Interface [17]

Service Design and in particular Service Blueprinting can help organisations and critically higher education, to better understand, assess and improve the services provided to both staff and students [18]. Service Design and Design Thinking can support any institute in becoming more focused on the student perspective, but it will also engage employees in creating new, or improving existing service offerings. Higher education is a service. A service is an interface with a customer. In any higher education institute, there are many services provided at various stages of the student lifecycle, from prospect to alumni.

In order to take the design process from initial information and insight gathering, through to defining the right problem and delivering a solution to fix this problem, there are a number of key elements. Many authors agree that a service is made up of a series of touchpoints and an evolving attitude that is user-centred at its core is central in defining how the touchpoints relate to each other and the user [17] [18]. 
At present, in the public sector, Bailey et al [1] have found that a great deal of Service Design happens without any professional or hands-on design involvement, which is what needs addressing. Service Design has the power to unleash creativity and innovation in the higher education sector, essentially because it is a co-creative process that focuses on students as customers.

The problem with Service Design seems to be the difficulty in selling it to the organisation and designers themselves find it difficult to explain what Service Design really is. The word design can often bring a sense of mystery to a process and the challenge then is to encourage employees not to be afraid of design and eliminate the perception that they have to be highly imaginative people to use design tools and techniques. Building in-house capabilities in Service Design tools and techniques is therefore vital to embedding design in any organisation, as these in-house 'designers' will have direct knowledge of how things work.

\section{Organisational Change}

A widely recognised belief when delivering any kind of change is the vital importance of creating a vision, selling that vision to all ranks of the organisation and clearly communicating the vision while drumming up some excitement [11]. This vision should be easily understood and will motivate people towards the change. Kotter [11] cautions that without a sensible vision, a transformation effort can easily dissolve into a list of confusing and incompatible projects that can take an organisation in the wrong direction or nowhere at all. By their nature Service Design tools allow people to work towards a vision that is user-centred. Certainly a vision is important but what many organisations lack are leaders at all levels that can make this vision a reality. Martins and Terblanche [14] recognise the importance of creativity and innovation in the change process and emphasise that embedding a fresh and creative culture is paramount to achieving real change.

Change needs to be driven from the top, but it is also imperative that there is buy-in from stakeholders at all levels of the organisation. It is not adequate to include staff in a co-creation and design process; they need to appreciate what the change is about, how it will influence their day-to-day jobs, and how it has the potential to transform the student experience. It is important to understand the end goal and how their ideas should be at the forefront of this change process. It is clear that in order for change to be adopted it must be co-created and the challenge co-defined from grassroots to the top level of the organisation.

It has conclusively been shown that organisation silos have a huge impact on change and are a constant stumbling block as iterated by a number of aurthors [4] [20]. Where there is an existing issue of organisational silos, individual departments tend to focus on their cog in the wheel and not the process in its entirety. It seems clear that a lack of integration across organisational departments in providing a streamlined cohesive service to users is one of the main hurdles to jump when effecting change. Departments are often focused on fire-fighting immediate operational issues and do not always get the opportunity or the time to be innovative or experiment with diverse ways of working.

Various authors have considered the culture matter and Liedtka [12] asserts that you need people at every level on-board and eager, not just those at the top of the chain. Kotter [11] substantiates this and believes it is important to 'make the change stick' by fostering a new culture. A new culture will develop over time through small consistent innovations; this can take years and must not be rushed.

Kotter [11] points out that if change is needed within a specific department, then that department manager is fundamental. He emphasises that if these individuals are not 'new leaders, great leaders, or change champions, phase one can be a huge challenge'. Both this authors experience and the existing literature demonstrate that it can sometimes be necessary to implement a small change project in order to convince a department manager of the potential of such a change initiative.

With any change initiative, achievable, shortterm targets need to be set, and once accomplished, will motivate people to persist and keep trying. The celebration from quick-wins will create buy-in for future change projects. It is important to consider current work habits and communication styles of individuals and groups, and attempting to change these to leverage more sophisticated alternatives.

Hammer and Champy [10] propose that process re-engineering must be an all-or-nothing organisation-wide strategy and cannot be carried out in small careful steps. Based on the existing review of change projects in higher education, incremental change, along with participation from all stakeholders is imperative, particularly when the culture of an organisation is resistant to change. Other authors disagree with Hammer and Champy [10] and harmonise that the short-term wins are important to create momentum and celebration and any significant organisational improvement. Kotter [11] highlights that 'commitment to produce shortterm wins helps keep the urgency level up'.

According to Gouillart [9], in order to implement change and transform processes in an organisation, employees and external stakeholders need to be jointly engaged in designing the new model of the business. He stresses that many conventional change approaches run out of steam because of their internal 
and top-down character. Bailey et al., [1] concur with other authors and claim that it is far easier to do 'small scale repurposing of services' rather than large scale organisational change.

Many authors refer back to the organisation culture, and the attitudes and behaviour of the employees and management providing the service, as having a huge impact on an organisations interaction with its customers and employees. Bailey et al., [1] acknowledge that public service change necessitates people being involved in the change from the start; these people being the public, citizens and users of a public service. This would in turn lead to users adopting the change and embracing the new way of doing things. So how then can one transform an existing organisation to becoming design-friendly and reshape the existing cultural standards? Change is constant and an organisations ability to be proactive to change rather than reactive will determine its success and agility.

Although up until now the use of design as a way to transform public sector organisations has been on the small scale, there are examples of large scale transformational change such as the Helsinki Design Lab and Nesta's Creative Councils project. However, much of the literature seems to overlook the possibility of small incremental change being delivered from the bottom or middle of the organisation and the impact this approach could have on the journey towards organisational change. Overall, there is not enough existing research on using Service Design as a bottom-up approach towards transforming an organisation into an innovative, progressive, efficient and user-centred one.

\section{Culture}

Organisation culture is central to the running of an organisation. As it is intangible and vague, the type of culture that exists in an organisation can often be difficult to define. It is based on tradition and can be very powerful in determining how people work, interact with each other and make decisions. In order for innovation to occur, the existing culture must first be understood. A strategy and structure needs to be put in place that allows behaviour to change in a positive way. Improving communication across departments can be a first step in the right direction. Organisations need to shift their attitude towards a culture focused on innovation.

Culture represents the behaviours that people develop and reveal over time [4]. Changing behaviour has a direct influence on any culture. The focus needs to become about thinking differently and behaving differently. At the same time Kotter [11] acknowledges that an individual's behaviour within a team or organisation influences the wider behaviour and whether collaboration, conversations and connections take place.

The public sector is often considered to be a risk and change-averse culture and one that is not supportive of creativity and innovation. Bureaucratic and hierarchical in make-up, along with internal politics, provides a strong influence over what goes on and can be hard to crack. Flexibility and a willingness to adapt are not key characteristics of the public sector and are very dependent on individual leaders and managers. There is a need to deliver public services in a better way by means of a usercentred approach.

Martins and Terblanche [14] reveal that organisation culture forms an essential part of the general functioning of an organisation and this is a contributing factor as to whether creativity and innovation can occur. They propose that culture influences the degree to which creativity is encouraged, sustained and applied and the conflicting power of culture in an organisation is that it diminishes efficiency. Matthews et al., [15] indicate that past practices, hierarchical structures and silos within an organisation can present as barriers to change and innovation. Indeed Battarbee et al., [3] refer to an 'unsympathetic culture' that is not focused on customer experience and nurturing an empathic mind-set can help to foster a new culture.

One author highlights that staff at all levels should be trained in the tools of Design Thinking. Brown [5] believes that a change in culture to one focused on innovative activities and attitudes can be done through the introduction of new tools, setting expectations up-front and measuring the innovation that is required. He favours workshops as a method to expose people to Design Thinking and reveals that pilot projects will help market the benefits of Design Thinking within an organisation. This was validated in a recent pilot project in the author's organisation where it was shown that small innovations can have a positive impact and lead to more change. Management need to promote continuous improvement while at the same time allowing time for new ideas and experiments to flourish.

There seems to be little agreement in the literature on the type of culture needed to improve creativity and innovation, however, Martins and Terblanche [14] identify the dimensions that influence the degree to which creativity and innovation takes place:

1. A strategy that encourages creativity and innovation in the implementation of new products and services

2. A flexible structure that encourages teamwork and collaboration across existing silos

3. Support mechanisms that encourage new ideas and provide time, information, resources and technology for this 
4. Employee and management behaviour that encourages innovation, idea generation, risk taking and support for change

5. Open communication between individuals, teams and departments

A lot of what is wrong with public sector organisations is their tiered structure and management style. Many of the existing public services lack the ability to be agile and efficiency is often defined in terms of a financial return rather than a customer experience. There is a strong link between culture and change and it can be assumed that in order to implement any positive change, there has to be a shift in the organisational values. Influencing change in individual departments can involve identifying a sub-culture that perhaps doesn't exist organisation-wide. Every organisation will have a different path to changing mind-set and figuring out what that path is can be a brave encounter. Design Thinking tools may help an existing culture to become more open and willing to see things in new ways but can they encourage innovation in a sustainable way?

Many higher education institutions in Ireland have a strong management rather than leadership culture. It is leaders that will play an important part in shaping a new culture based on their own desire for continual improvement. It is these leaders that will be able to empower and cultivate employees into a new era of change and innovation.

Changing mind-set and culture to stimulate creative thinking among the front-line employees will build and foster a more innovative approach to 'how we do things around here'. Harnessing new ideas can make the organisation more effective and better equipped to fix problems before they happen.

\section{Design Thinking}

Brown [5] describes Design Thinking as 'exploring different possibilities'. He suggests that it is 'open-ended, open-minded, and iterative, but that a process fed by Design Thinking will feel chaotic to those experiencing it for the first time'. He reminds us that it will take an organised, consistent and efficient approach to achieve organisation-wide change.

Initiating administrators into the mysteries of Design Thinking can unleash passion and energy and creativity. It can also elicit new levels of engagement from people who may have spent so much time fighting the system that they could barely imagine having a role in redesigning it. Without a sustained commitment and an integrated approach, an initial effort might be overwhelmed by day-to-day exigencies of running an organization [5].

There may be resistance to adopt a Design Thinking method for a number of reasons but if employees can understand the benefit then it may be easier. In a number of organisations, design teams exist independently, but how then can a Design Thinking approach be embedded within areas of an organisation once the design team leave? How can design tools be entrenched within an organisation, which prefers to be familiar with their current way of doing things, even if that current approach lacks efficiency? Employees need to be empowered to use the tools themselves without supervision from the designers.

Battarbee et al., [3] observe that Design Thinking allows us to come up with unique solutions to tackle everyday problems, with results that are more meaningful for the users of that solution. It allows one to focus on real-life behaviour using co-creation and observation, rather than coming up with solutions that we think may work.

Design Thinking is unlikely to become an exact science, but as with the quality movement, there is an opportunity to transform it from a black art into a systematically applied management approach. The trick is to do this without sucking the life out of the creative process - to balance management's legitimate requirement for stability, efficiency and predictability with the design thinkers need for spontaneity, serendipity, and experimentation [5]. The tangible benefits will have to be clear if Design Thinking is here to stay.

While trying to embed Design Thinking as a new tool for higher education, it is imperative not to lose any of the innovation, imagination and inspiration that this process brings by trying to put structure on it. Design Thinking can be practised, by everybody in all parts of the organisation, from front-line staff to senior management, as a problem-solving approach.

'Co-creative transformation, mixing bottom-up and outside-in approaches, produces the infectious enthusiasm and momentum that motivates middle and upper management to invest the necessary resources for change' [9]. On the other hand, Liedtka [12] discusses the strategies of business thinking versus Design Thinking.

Business thinking is predicated on assumptions of rationality and objectivity. Its decision driver is cold, clean and economic logic. Reality is precise and quantifiable. In contrast, Design Thinking assumes human experience, forever messy, as its decision driver and sees true objectivity as an illusion. Reallife behaviour rather than theory is what matters for design [12].

In his book, Brown [5] maintains that 'the emphasis on fundamental human needs, as distinct from fleeting or artificially manipulated desires, is what drives Design Thinking to depart from the status quo'. He argues that there are design thinkers in every organisation and we need to seek them out, 
foster them and free them up to be creative people and potential change champions.

Beckman and Barry [4] define Design Thinking as a problem solving process that involves actors from many disciplines using tools, methods and language that are diverse from normal everyday business function.

A number of authors contend that selecting the right people for any change project is an important feature for success [15] [20]. They stress the importance of selecting the right people for the job, people who are motivated by change and want to be involved, but also people that have integrity and respect within the organisation. Change champions or design champions will be the vehicle for transformation and the agents of change. They will not let barriers get in the way, and they will seek out opportunities to bring the organisation on a new journey of design innovation.

Changing the relationships between the main actors involved in delivering a service, and those using a service, will help to build better service capabilities. Empathy will assist in discovering the moments of truth for all actors along the journey. Unless a change champion walks in someone else's shoes, they will never gain a true understanding of their experience, and their thinking will be based on assumptions. Empathy involves immersing oneself in the experience of the user, observing the user and engaging with the user. This is where an inside-out service designer can have vast benefits, working alongside the actors inside and outside the organisation.

Kotter [11] emphasises a 'see-feel-change' approach rather than an 'analyse-think-change' approach and suggests that in order to change behaviour, we should focus on people's feelings rather than thoughts; this is precisely what empathy does. Battarbee et al., [3] insist that when an organisation allows itself to be motivated by an understanding of people's needs, it can 'unlock the creative capacity for innovation'. This sort of attitude needs to be supported and fostered and it needs enthusiastic champions to 'keep empathy alive'.

The term Design Thinking can sometimes create mystery and uncertainty, and rather than trying to sell Design Thinking as a new approach, the focus should be on the benefits it brings; the outcomes should speak for themselves. Human needs are fundamental to Design Thinking and these needs should drive innovation. Having the right people involved is essential, people who understand the need for change, and can be empathetic towards the users.

\subsection{Design and the Public Sector}

Changing public services has to begin with people and Design Thinking enables government agencies to put people at the heart of the design process. There are a number of design initiatives underway in the UK but not many in Ireland. Organisations like The Design Council and Future Gov are currently working with many local and national government agencies to help them transform their services using design.

The Design Council [7] created the Public Sector Design Ladder, Fig. 2, in order to demonstrate that design can be applied at different levels and it can be used as a 'diagnostic tool and roadmap for progression'.

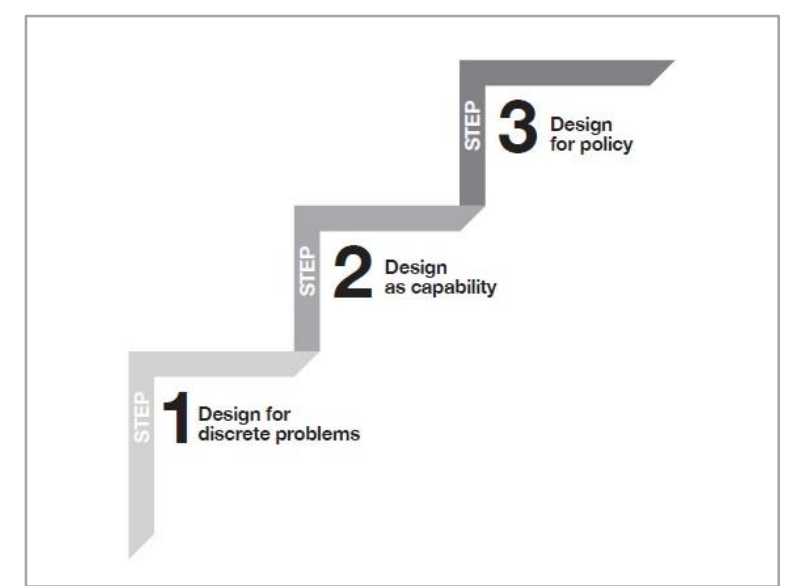

Figure 2. Public Sector Design Ladder [7]

Some examples of how Design Thinking can be adopted in the public sector include Lewisham Council. A project was initiated with the aim of embedding Service Design within the council among employees as a new way of working. A 'learning by doing' approach was used where 'front-line staff were armed with tools and techniques so that they, rather than the designers, could go out to find and fix problems' [7]. As a result of this project, staff morale at the council improved, cost savings were introduced and customers received a more efficient service.

Another example is the UK's redesign of the government's digital services by engaging with users to deliver simple and fast services online. Their aim was to streamline the services they delivered online and merge the websites of all government agencies into one portal making them 'simpler, faster, clearer' [7]. This included 24 ministerial departments and 331 agencies and public bodies. The team continues to use design to refine the user experience and spread design throughout the government.

A further example and one in higher education that has to be mentioned as it was the inspiration for research at CIT, is the JISC Enrolment Project in conjunction with University of Derby. They used a Service Design approach to improve the student experience from pre-entry to 'readiness for learning'. Baranova et al., [2] discovered that rather than 
assuming they knew what the student wanted, they 'actively sought their input as end-user designers and co-producers of their own student experience'. They continue to use Service Design as a methodology at Derby to focus on student retention throughout the delivery process. At the University of Derby, Baranova et al., [2] found that Service Design was a powerful tool to engage not only the front-stage and back-stage staff involved in the service delivery but also management. It was a transformative way to make everyone see the complexity of these processes, from the student perspective, and seeking student input in redesigning these services was a new approach, that could add value to both the university and the student experience.

\subsection{Embedding Design Thinking}

Design Thinking is an enabler and a skillset that can be applied to challenges within any organisation. The challenge is to enable 'non-designers' to participate and facilitate design-led change without the need for a designer. This will ensure design is embedded in a sustainable way. It is necessary to create design champions who can propose and apply design methods in a positive way. Employees and managers need to be trained to apply design tools in their own environment, which will lead to some incremental improvement in an existing process or service. There is modest research on this topic and little existing evidence on how to embed design as an approach in the public sector.

When selecting the right people to become champions, much of the literature advises selecting people who are credible, motivated and already have some desire for change. In order to change behaviour it is essential to expose people to a new way of working. Matthews et al., [15] use the term 'design interpreter' as a necessary human force to 'influence and synthesise opportunities across the organisation'. Designers play an important social role when delving into multidisciplinary project teams that may have historical nuances.

Design Champions, or change champions that use design approaches, can add value and credibility to any project. These champions need to ensure that employees don't revert to their old ways of working. One needs a 'community of enablers' to work together and make sure the good ideas come to fruition. Tjendra [19] agrees and claims that several elements are necessary to establish and embed a design culture including top-down advocates and 'empowered ground-up employees lead by the process champion middle manager who is preferably a designer'.

\subsection{Empathy and Engagement}

Empathy is an important first step in any design process as it allows the designers and non-designers to have a deep understanding and feeling of people's needs and issues. In understanding these requirements, stakeholders become more open to solving design challenges that are truly meaningful for the users. 'Research shows that when we are empathetic, we enhance our ability to receive and process information' [3]. Sometimes within large organisations, the culture can be insensitive to what users are really undergoing and this can be as much to do with the daily stress of keeping operations going.

There can also be a culture of insensitivity to users based on employees own feeling that their needs are not being met, that no-one is listening to them. People behind the delivery of a service, in particular those at the front-line have first-hand knowledge of user issues.

As an institute, the intent should be to fulfill the needs of our students. Sometimes when talking about implementing change at CIT, words like process and streamline and service and re-engineering are used. This language needs to become more customerfocused so that it is understood by everyone, swapping those words for a humbler language; simple steps, good experience, easily understood, clarity, improve the experience, provide a better service, support staff and students are phrases that can be one of the many steps on the road to transformation.

Dale Carnegie [6] expressed that 'the deepest urge in human nature is the desire to be important'. Involving employees in a co-design process increases employee engagement, because humans have a distinctive urge to feel that their actions and ideas can contribute to a larger change initiative. The Japanese have a name for involving and respecting all ideas and contributions from employees; kaizen, or continuous improvement. By listening to employees in a co-design process, an organisation can increase commitment while ensuring that there is continuous change benefiting everyone, not only the users.

In other words, there is always room for improvement and continuously trying to become better. At CIT, co-creating gradual incremental improvement rather than fundamental change is a more achievable goal.

\section{Design Thinking and Leadership}

Every change undertaking needs a leader with a vision who will be empowered with a new direction for the future. Kotter [11] defines the function of a leader as one who implements change, but can that leader guide other managers and leaders to a new 
way of design-led change in an organisation that is traditionally slow to adapt? Higher education institutions are currently under pressure to change from both internal stakeholders, and outside-in pressure from industry.

Leadership is about building on existing relationships, coaching, mentoring and according to Carnegie [6] 'helping people to achieve what they are capable of'. 'Design Leadership is about empowerment, vision and driving change through design. Design leaders nurture creativity by embedding the design function into organisations' [16]. Design Leaders are the ones that plant the Design Thinking seed in an organisation and encourage stakeholders at all levels to adopt design processes in some way.

Facilitation, communication, good interpersonal skills and empathy are essential for a leader that wants to integrate Design Thinking into an organisation. Building trust and a shared interest can influence people to collaborate, ideate and define the real problem before focusing on a solution. Cocreation is about building the human bridges across departments and creating connections and a joint focus on the customer experience.

It takes actions rather than words to create this influence. If people can see the benefits of these actions then are likely to come on board and work together to create change. Communication is central to turning intention into action. Encouraging people to take risks, communicate, be open, and share thoughts and feelings, takes time and patience. Employees need to understand how Design Thinking can help them in their everyday jobs and make their lives easier. People need to feel that they are a valued part of the organisation. Design Thinking leadership should involve incremental and continuous underpinning using champions and advocates to spread the word. Carnegie [6] believes that 'you make them want to come along. You ride, you go and you just suck everybody else with you'. CIT needs to build a repository of design thinkers that can spread the word across projects and opportunities in every area of the organisation.

Matthews et al., [15] observe that design leadership is more than a leader with design skills or training, but someone who has an understanding of the day-to-day business and who can 'synthesise opportunities across the organisation'. Gloppen [8] reiterates this and adds that design leadership is about helping to turn business strategies and visions into actual solutions. Miller and Moultrie [16] insist that it is the design leader who needs to encourage all within the organisation to embrace the design process as a new way of how we do things around here.

Leaders can encourage more experimentation, and by using Design Thinking as a tool, they can develop value for customers at every touchpoint. The difficult part is getting people to believe the message and that can only come from a credible design leader, someone who has earned trust and a reputation for delivering change, based on the needs of the participants. 'Designers and managers are in this together; try and show each other the way. Anyone trying to innovate in a big bureaucracy needs all the help they can get' [12].

Design leadership is about facilitating change and creating opportunities which allow organisations to deliver more cohesive services. As leaders are meant to motivate and energise employees, design leaders have a vision for change and help to empower people to become more focused on turning that vision into reality. When it comes to Design Thinking, a leader needs to inspire colleagues to start with a blank sheet of paper. Rather than trying to fix something that exists but never really worked, Design Thinking will allow people to explore all possible options and to 'resist reliability' [13].

A leader must inspire people to think laterally and explore options. It is about creating a vision and in order to develop innovative services, a leader is required. Gloppen [8] describes Service Design Leadership as:

An approach where leaders in service organizations understand and use the power and value of design and Design Thinking's contribution to a visionary strategy process intended to create innovative services. Service Design leadership involves a multidisciplinary and interdisciplinary synthesis approach to problem solving and innovation.

Design Leadership must be about helping people to jointly create a vision and helping them to use design tools to implement that vision. If we look at the perspective of using Service Design tools to innovate with regard to existing services, then a leader will enable and motivate a group to make small improvements and build on these improvements in an incremental fashion; it is keeping up the momentum that is important. This can be difficult in higher education as the academic year runs in cycles and different services are delivered at different stages of each cycle. Memories are blurred after each stage in the cycle, sometimes it is a full year before we need to deliver that service again, and we almost erase the pain-points from our minds.

Flexible collaboration between leaders, designers and front-line employees within an organisation will require a new mind-set and outlook that is focused on delivering benefits and value for customers through design-stimulated service innovations.

\section{Conclusion}

Design Thinking in Ireland and in particular Service Design is still an emerging field and 
specifically its use in higher education and the public sector.

This paper is an initial discovery to see how Design Thinking can be embedded in a higher education institution, in order to create change and enhance the student experience. It focused on six key areas, and realised that in order to introduce Design Thinking and Service Design as methods for change, a leader first needs to create a vision for that change. Communicating that vision and getting employees on board is not an informal task, and the existing culture is a contributing factor to the degree to which innovation can occur. Organisation culture plays a fundamental role in the performance of any organisation. Design Thinking can help to break down the barriers to change and integrate opportunities across the organisation. Design Thinking is a process that focuses on the user and allows a team to come up with a unique solution.

In summary, the literature advises the following:

- Innovation needs to become a core activity in the organization.

- Service Design tools and methods can help an organisation to innovate.

- Change can be disruptive and individuals at every level of the organisation need to involved and energized.

- Design Thinking as a new approach can help to change an existing culture.

- Leadership is vital to encourage those within the organisation to embrace the design process as a new way of working.

In the context of the higher education sector further research will be conducted in the coming years to assess these theories. CIT are currently working to define and formalise a Student Lifecycle to be used as a building block for refining internal processes. It is this vision for change that will inspire and focus minds on the next steps of the journey. Rather than just implementing a number of change projects, there is a gap in the existing research, to discover if Design Thinking can enable an organisation of this type, to move towards becoming a more efficient and automated administration. The change management, people and culture aspect of the initiative will require further research and effort. CIT needs new ideas and a fresh approach where previous attempts to re-design processes have failed.

It is clear that there is a dearth of literature available on Design Thinking leadership and the area lacks research especially in the public and higher education sectors. This gap that will be addressed on this research journey while effecting incremental change projects to deliver student-centric services.

\section{References}

[1] Bailey, J., Julier, J., Kohut, T., (2014) 'Restarting Britain2: Design and Public Services', Annual Review of Policy Design 2, 1-10. https://www.designcouncil.org.uk (28 April 2015)

[2] Baranova, P., Morrison, S., \& Mutton, J. (2010) 'Service design in higher and further education', JISC Briefing Paper; http://publications.cetis.ac.uk/wpcontent/uploads/2011/02/Service_Design.pdf (28 April 2015).

[3] Battarbee, K., Fulton Suri, J., \& Gibbs Howard, S. (2014) 'Empathy on the Edge: scaling and sustaining a human-centred approach in the evolving practice of design', IDEO; http://www.ideo.com/images/uploads/news/pdfs/Empathy_ on_the_Edge.pdf (28 April 2015).

[4] Beckman, S. L., \& Barry, M. (2007) 'Innovation as a learning process: Embedding design thinking', California Management Review, 50(1), 25.

[5] Brown, T. (2009) Change by Design: How Design Thinking Transforms Organizations and Inspires Innovation, HarperBusiness, New York.

[6] Carnegie, D., (1995) The Leader in You: How to Win Friends, Influence People and Succeed in a Changing World, Simon \& Schuster, New York.

[7] Design Council (2013) 'Design for Public Good', Annual Review of Policy Design 1, 1-50, Design Council; https://www.designcouncil.org.uk (28 April 2015)

[8] Gloppen, J. (2009) 'Service Design Leadership', ServDes 2009: First Nordic Conference: Service Design and Service Innovation.

[9] Gouillart, F. J. (2014) 'The race to implement cocreation of value with stakeholders: five approaches to competitive advantage', Strategy \& Leadership, 42(1), 28 .

[10] Hammer, M., and Champy, J. (2003) Reengineering the corporation: a manifesto for business revolution, HarperBusiness, New York.

[11] Kotter, J. P. (1995) 'Leading Change - Why Transformation Efforts Fail', Harvard Business Review.

[12] Liedtka, J. (2010) 'Business Strategy and Design: Can this Marriage Be Saved?', Design Management Review, 21(2), 6-11.

[13] Martin, R. L. (2009) Design of Business: Why Design Thinking is the Next Competitive Advantage, Harvard Business Review Press, Boston.

[14] Martins, E. C., and Terblanche, F. (2003) 'Building organisational culture that stimulates creativity and innovation', European Journal of Innovation Management, 6(1), 64-74. 
[15] Matthews, J.H., Bucolo, S., Wrigley, C., (2012) 'Challenges and opportunities in the journey of the designled innovation champions', Proceedings of the DMI 2012 International Research Conference, pp. 768-775.

[16] Miller, K., \& Moultrie, J. (2013) 'Understanding the Skills of Design Leaders', Design Management Journal, 8(1), 35-51.

[17] Moritz, S. (2005) Service Design - Practical Access to an Evolving Field, London.

[18] Ostrom, A. L., Bitner, M. J., and Burkhard, K. A (2011) 'Leveraging Service Blueprinting to Rethink Higher Education: When Students Become 'Valued Customers,' Everybody Wins', Center for American Progress.

[19] Tjendra, J. (2013) 'Why Design Thinking Will Fail', Innovation Excellence, http://www.innovationexcellence.com/blog/2013/02/25/wh y-design-thinking-will-fail/ (28 April 2015)

[20] Von Stamm, B. (2008) Managing Innovation, Design and Creativity (2nd edition), Wiley \& Sons, Chichester, UK. 